\title{
Repeated surgery for recurrent Crohn's disease: does the outcome keep worsening operation after operation? A comparative study of 1224 consecutive procedures
}

\author{
Francesco Colombo ${ }^{1}$ - Alice Frontali ${ }^{1}$. Caterina Baldi ${ }^{2} \cdot$ Maria Cigognini $^{2} \cdot$ Giulia Lamperti $^{1} \cdot$ Carlo A. Manzo $^{2}$. \\ Giovanni Maconi ${ }^{3}$. Sandro Ardizzone ${ }^{3}$. Diego Foschi ${ }^{4}$. Gianluca M. Sampietro ${ }^{2}$ (I)
}

Received: 22 April 2021 / Accepted: 2 October 2021 / Published online: 1 November 2021

(c) Italian Society of Surgery (SIC) 2021

\begin{abstract}
Complicated Crohn's disease (CD) will require surgical treatment during patients' lifetime, with a considerable recurrence rate requiring additional surgery. The present study is a retrospective analysis of a prospectively maintained database in an IBD Tertiary Centre that included all the consecutive, unselected patients undergoing surgery for CD between 1993 and 2019. Patients treated with small bowel resections, colonic resections, conventional and non-conventional strictureplasties were considered. The aim was to evaluate morbidity and long-term recurrence of repeated surgery. Among the population included, the following procedures were performed: 713 (58.2\%) primary surgery (group S1), 325 (26.5\%) first recurrence (group S2), and 186 (15.3\%) multiple recurrences (group S3). Patients undergoing repeat surgery were older $(p<0.0001)$ and had a longer disease duration $(p<0.0001)$, extended disease $(p=0.0001)$, shorter time frame to first surgery $(p<0.0001)$, nutritional impairment $(p<0.0001)$, and a history of aggressive medical therapy $(p=0.04)$. Patients undergoing surgery for recurrences required higher complexity level surgery, with more conservative approaches $(p=0.0004)$ and a higher ostomy number $(p=0.06)$. Recurrent patients had higher short bowel syndrome rate $(p<0.0001)$, higher minor $(p=0.04)$ but not major $(p=0.2$ ) postoperative complications rate. The 10 -year surgical recurrence rate was $18 \%$ for group S1, 27\% for S2, and $48 \%$ for S3, with significant differences at the log-rank test. Repeated surgery for complicated CD was associated with an increased rate of minor, but not major complications, requiring high-risk surgery, with a major ostomy rate and short bowel syndrome, and is associated with an increased long-term surgical recurrence, even on strictureplasty sites.
\end{abstract}

Keywords Crohn's disease $\cdot$ Surgery $\cdot$ Postoperative complications $\cdot$ Recurrence $\cdot$ Outcomes

$\begin{array}{ll}\text { Abbreviations } \\ \text { IBD } & \text { Inflammatory bowel disease } \\ \text { CD } & \text { Crohn's disease } \\ \text { SP } & \text { Strictureplasty } \\ \text { NCSP } & \text { Non-conventional strictureplasty }\end{array}$

Gianluca M. Sampietro

gianluca.sampietro@unimi.it; gmsampietro@asst-rhodense.it

1 Division of General Surgery, ASST Fatebenefratelli Sacco, Luigi Sacco University Hospital, Milan, Italy

2 Division of General and HPB Surgery, ASST Rhodense, Rho Memorial Hospital, Corso Europa, 250, Rho, 20017 Milan, Italy

3 Division of Gastroenterology, ASST Fatebenefratelli Sacco, Luigi Sacco University Hospital, Milan, Italy

4 Second Unit of General Surgery, Multimedica IRCCS, S. Joseph Hospital, Milan, Italy

\section{Introduction}

Crohn's disease (CD) [1] is a chronic, pan-intestinal, inflammatory bowel disease (IBD) of unknown etiology, with a significant impact on patients' quality of life. Despite the encouraging results of biologics on the disease clinical history, the large majority of patients may undergo surgery at some point, and nearly $50 \%$ will recur within $10-20$ years [2].

Several predictors of surgical recurrence have been identified, such as genetic predisposition, young age at diagnosis, surgery within one year of diagnosis, smoking habit, penetrating disease behavior, upper-GI location associated with stricturing behavior, perianal disease, mesentery characteristics, bowel wall thickening and endoscopic recurrence within one year after surgery [2-14]. Laparoscopy is nowadays the gold standard for primary surgery, and also in selected cases of recurrent disease, if adequate surgical expertise is 
available $[15,16]$. Regardless, primary surgery is performed by open or laparoscopic approach, in case of recurrence surgery is potentially associated with high postoperative complications rate due to altered anatomy, complex adhesions, and hidden perforating disease with abscesses and fistulas $[17,18]$. Furthermore, repeated surgery has been reported to adversely affect long-term surgical recurrence [19, 20]. Few reports available in literature assess patients' outcome for iterative surgery and tend to be focused on ileocecal resections [21, 22]. No study has been reported considering the outcome in patients with multiple disease locations, involving the ileum and the colon, treated by resections and strictureplasties (SP), and undergoing repeated surgery.

Aim of the present study was to assess safety and efficacy of repeated surgery in a consecutive, unselected series of $C D$ patients from a tertiary IBD Center.

\section{Materials and methods}

\section{Study population}

Patients operated for primary or recurrent CD between January 1993 and December 2019 were registered in the prospective Crohn's Disease Clinical Auditing and Research Database (CD-CARD) of the "Luigi Sacco" University Hospital, including demographic, clinical, surgical and follow-up data. Surgical decision-making process included formal MultiDisciplinary Team meeting (MDT), involving gastroenterologists, pediatricians, surgeons, pathologists and radiologists, based on the complete preoperative work-up using CT scan or MRI, bowel ultrasonography, and endoscopy. All consecutive, unselected patients were considered eligible for the analysis and retrospectively reviewed, regardless of the number, location, and behavior of diseased segments, and the type and number of treatment adopted, such as small bowel and/or colonic resections, conventional (SP) and nonconventional (NCSP) strictureplasties. No exclusion criteria were applied. Patients were divided into three groups, according to the surgical history: primary surgery group (S1) including patients at first operation; patients at second operation due to surgical recurrence forming the secondary surgery group (S2); and patients undergoing three or more surgeries were included in the tertiary surgery group (S3).

\section{Surgical procedures}

After an accurate intraoperative staging of all CD intestinal locations and characteristics, a "per-segment" approach was adopted for every single lesion [16, 23]. As previously reported, small bowel segments affected by penetrating disease were treated by minimal resection with mesentery removal. Absence of residual lumen, thick and retracted mesentery and massive lymphadenopathy were further indications for small bowel resection. Intestinal continuity was restored by functional end-to-end anastomosis, either manual or stapled. Fibro-stenotic disease was treated by conventional strictureplasty (SP) in case of short lesions (Heineke-Mikulicz technique), and non-conventional strictureplasties (NCSP) in case of multiple and close strictures, or long diseased segment, or disease located to the terminal ileum or a previous ileo-colonostomy. Large bowel disease locations were always treated by resection, following colonic vascular anatomy, and with mesentery removal $[3,6,7,9$, 23].

A planned temporary ostomy was performed in patients at high risk for post-operative septic complications, identified by the presence of two or three among preoperative highdose steroid and/or anti-TNF treatment, intra-abdominal septic complications at time of surgery, and poor nutritional status.

\section{Outcome measures}

The primary endpoint was to compare the peri-operative morbidity rate among the three groups (S1, S2 and S3). Post-operative complications were classified according to Clavien-Dindo classification in terms of maximum complication for patient developed during hospital stay or within 30 days from surgery [24]. Patients receiving total parenteral nutrition (TPN) or blood transfusion in the contest of a scheduled perioperative optimization were not considered as Clavien-Dindo grade II. Severe postoperative morbidity was defined as any complication graded III or IV, and mortality as grade V. Secondary endpoints were to evaluate clinical and biochemical factors and long-term surgical recurrence rate, defined as the need for a new surgical procedure due to disease recurrence, associated to repeated surgery. Short bowel syndrome was defined as a reduction in gut function below the minimum necessary for absorption of macronutrients and/or water and electrolytes, requiring enteral or parenteral supplementation.

\section{Statistical analysis}

Quantitative data were reported as mean and standard deviation $( \pm \mathrm{SD})$. Continuous variables were compared using analysis of variance (ANOVA) or two-tailed, unpaired, Student's $t$ test, and proportions were compared using twotailed, Fisher's exact or Chi-square test, where appropriate. Time-to-event estimates for surgical recurrence were calculated using the Kaplan-Meier function, and compared using the log-rank test. The level of significance was set at $p \leq 0.05$. Statistical analysis was performed using STATISTICA 8 (data analysis software system), Stat Soft Inc. The CD-CARD database and the study were approved by 
the ethics committee of our Institution (Approval Number 1247703013039, 12/12/2013).

\section{Ethical considerations}

The study was conducted according to the ethical standards of the Declaration of Helsinki (2013 version) and reported according to the Strengthening the Reporting of Observational Studies in Epidemiology [STROBE] guidelines [25, 26].

\section{Results}

During the study period, 1224 consecutive patients were operated at "Luigi Sacco" University Hospital (Milano, Italia) for complicated CD: 713 (58.2\%) for primary surgery (group S1), 325 patients at first surgical recurrence (26.6\%), and 186 patients with multiple recurrences (group S3, 15.2\%). Patients' characteristics are reported in Table 1. Considering the Montreal Classification [11], the groups were similar in terms of gender, perianal disease, smoking habit, IBD family history, extra-intestinal manifestations,

Table 1 Patients characteristics

\begin{tabular}{|c|c|c|c|c|}
\hline & $\begin{array}{l}\text { First surgery } \\
\text { (S1) } n=713(\%)\end{array}$ & $\begin{array}{l}\text { Second surgery } \\
\text { (S2) } n=325(\%)\end{array}$ & $\begin{array}{l}3 \text { or more surgeries } \\
\text { (S3) } n=186(\%)\end{array}$ & $p$ \\
\hline Age & $39.9 \pm 14.3$ & $42.5 \pm 12.9$ & $46.1 \pm 12.3$ & $<0.0001$ \\
\hline Gender M/F & $434 / 279(61 \%, 9 \%)$ & $186 / 139(57 \%, 3 \%)$ & $102 / 84(55 \%, 45 \%)$ & 0.2 \\
\hline Age A1, A2, A3 & $\begin{array}{l}56,473,184 \\
(8 \%, 66 \%, 26 \%)\end{array}$ & $\begin{array}{l}51,214,60 \\
(16 \%, 66 \%, 18 \%)\end{array}$ & $\begin{array}{l}31,133,27 \\
(17 \%, 72 \%, 15 \%)\end{array}$ & 0.0001 \\
\hline Location L1, L2, L3, L4 & $\begin{array}{l}459,96,71,87 \\
(64 \%, 14 \%, 10 \%, 12 \%)\end{array}$ & $\begin{array}{l}190,29,44,63 \\
(58 \%, 9 \%, 14 \%, 19 \%)\end{array}$ & $\begin{array}{l}79,6,45,57 \\
(42 \%, 3 \%, 24 \%, 31 \%)\end{array}$ & 0.0001 \\
\hline Behavior B1, B2, B3 & $\begin{array}{l}18,286,409 \\
(3 \%, 40 \%, 57 \%)\end{array}$ & $\begin{array}{l}8,145,172 \\
(2 \%, 45 \%, 53 \%)\end{array}$ & $\begin{array}{l}5,75,106 \\
(3 \%, 40 \%, 57 \%)\end{array}$ & 0.7 \\
\hline Perianal disease $\mathrm{Y} / \mathrm{N}$ & $162 / 551(23 \%, 77 \%)$ & $80 / 245(25 \%, 75 \%)$ & $57 / 129(31 \%, 69 \%)$ & 0.08 \\
\hline Age at diagnosis & $33.2 \pm 14.3$ & $30.6 \pm 12.2$ & $28.9 \pm 10.6$ & 0.0005 \\
\hline Disease duration & $6.8 \pm 7.3$ & $12 \pm 6.9$ & $17.3 \pm 8.6$ & $<0.0001$ \\
\hline Time to 1 st surgery & $6.6 \pm 7.3$ & $3.4 \pm 4.6$ & $2.7 \pm 3.9$ & $<0.0001$ \\
\hline Smoking habit Y/N & $281 / 432(39 \%, 61 \%)$ & $145 / 180(45 \%, 55 \%)$ & $88 / 98(47 \%, 53 \%)$ & 0.08 \\
\hline Family history $\mathrm{Y} / \mathrm{N}$ & $71 / 642(10 \%, 90 \%)$ & $30 / 295(9 \%, 91 \%)$ & $19 / 167(10 \%, 90 \%)$ & 0.9 \\
\hline Extra-intestinal man. Y/N & $81 / 632(11 \%, 89 \%)$ & $43 / 282(13 \%, 87 \%)$ & $30 / 156(16 \%, 84 \%)$ & 0.1 \\
\hline Hemoglobin $(\mathrm{g} / \mathrm{L})$ & $12.4 \pm 1.9$ & $12.3 \pm 2$ & $12 \pm 1.9$ & 0.04 \\
\hline WBC count $\left(\times 10^{9} / \mathrm{L}\right)$ & $8371 \pm 3515$ & $8126 \pm 3301$ & $8193 \pm 3607$ & 0.5 \\
\hline C-reactive protein $(\mathrm{g} / \mathrm{L})$ & $3.8 \pm 6.8$ & $3.2 \pm 5.8$ & $4 \pm 8.9$ & 0.9 \\
\hline Albumin $(\mathrm{g} / \mathrm{L})$ & $35.7 \pm 9.4$ & $35.2 \pm 7.2$ & $34.1 \pm 7$ & 0.03 \\
\hline Pre-albumin (g/L) & $0.23 \pm 0.06$ & $0.22 \pm 0.08$ & $0.21 \pm 0.1$ & $<0.0001$ \\
\hline TPN Y/N & $130 / 583(18 \%, 82 \%)$ & $73 / 252(22 \%, 78 \%)$ & $51 / 135(27 \%, 73 \%)$ & 0.01 \\
\hline INT Y/N & $185 / 528(26 \%, 74 \%)$ & $87 / 238(27 \%, 73 \%)$ & $50 / 136(27 \% 73 \%)$ & 0.9 \\
\hline \multicolumn{5}{|l|}{ Preoperative therapy } \\
\hline No, 5-ASA & $345(48 \%)$ & $166(51 \%)$ & $82(44 \%)$ & \\
\hline Immunomodulators & $79(11 \%)$ & $43(13 \%)$ & $35(19 \%)$ & \\
\hline Biologicals & $66(9 \%)$ & $23(7 \%)$ & $24(13 \%)$ & \\
\hline Steroids & $189(27 \%)$ & $76(24 \%)$ & $37(20 \%)$ & \\
\hline Combo & $34(5 \%)$ & $17(5 \%)$ & $8(4 \%)$ & 0.04 \\
\hline \multicolumn{5}{|l|}{ Indication for surgery } \\
\hline Stenosis & $584(82 \%)$ & $274(84 \%)$ & $144(77 \%)$ & \\
\hline Fistula/abscess & $102(14 \%)$ & $39(12 \%)$ & $35(19 \%)$ & \\
\hline Refractory & $27(4 \%)$ & $12(4 \%)$ & $7(4 \%)$ & 0.3 \\
\hline
\end{tabular}

Montreal Classification for CD: age at diagnosis A1 $\leq 16$ years, A2 17-40 years, A3 > 40 years; disease location L1 terminal ileum, L2 colon, L3 ileocolonic, L4 jejunoileal; disease behavior: B1 non-stricturing non-penetrating, B2 stricturing, B3 penetrating; $p=$ perianal disease; Preoperative therapy was considered within 12 weeks before surgery

$T P N$ total parenteral nutrition, INT intraoperative transfusions 
and disease behavior, but recurrent patients were more likely to have their diagnosis before the age of 16 (A1) and multiple disease locations (L3 and L4) $(p<0.0001)$. The indication for surgery was similar among the three groups. However, patients in group S3 were significantly older $(p<0.0001)$, with a longer disease duration $(p<0.0001)$, younger age at diagnosis $(p=0.0005)$ and shorter time frame between diagnosis and first surgical procedure in comparison with the other groups. In terms of preoperative optimization, S3 group patients also presented with lower hemoglobin, albumin and pre-albumin values, need for parenteral nutrition $(p=0.01)$, and were more frequently treated with Anti TNF- $\alpha$ drugs in the last 12 weeks before surgery. Intraoperative findings are reported in Table 2. The shift of disease location, namely a recurrence on a different bowel district according to the Montreal Classification [11], was similar between $\mathrm{S} 2$ and $\mathrm{S} 3$ groups, but anastomotic recurrence was more common at first reoperation $(p=0.05)$, while strictureplasty recurrence at further surgeries $(p<0.01)$. The need for a colonic resection showed a downward trend in recurrences $(p=0.0004)$, such as perforating disease at surgery $(p=0.0001)$. Ostomies were more frequently performed after the second operation $(p=0.06)$.

Intestinal resections gradually decreased from $\mathrm{S} 1$ to $\mathrm{S} 3$ (58\% in S1, 51\% in S2 and 46\% in S3), while strictureplasties, both SP and NCSP, increased in all groups (42\% in S1, $49 \%$ in $\mathrm{S} 2$ and $54 \%$ in $\mathrm{S} 3$ ).
Duration of surgery, an indirect but reliable parameter of complexity of surgical procedure, progressively increases among groups. In particular, those patients receiving their previous operation at "Luigi Sacco" IBD Unit had shorter operating time than those referred from other hospitals after the first or further recurrences. Overall postoperative mortality and morbidity occurred in 6/1124 $(0.3 \%)$ and $353 / 1224(28.8 \%)$ patients, respectively. Postoperative complications according to the Clavien-Dindo classification are summarized in Table 3. Overall complication rate significantly increases after repeated surgery $(26.2 \%, 31.4 \%, 34.4 \%, p=0.04)$, but no differences were found among groups in terms of incidence of severe postoperative morbidity nor mortality (Clavien-Dindo III-V, $p=0.2$ ). An increased necessity of fecal diversion was present in the $\mathrm{S} 3$ group, with border-line statistical significance $(p=0.06)$. Intestinal failure (SBS) was significantly more frequent after repeated surgical procedures $(p<0.0001)$. In Fig. 1, the time-to-event estimates for surgical recurrence are reported. The cumulative proportions of recurrences at 10 years were $18 \%$ for $\mathrm{S} 1,27 \%$ for $\mathrm{S} 2$, and $48 \%$ for $\mathrm{S} 3$, with significant discrepancies at the logrank test.

Table 2 Intraoperative findings

\begin{tabular}{llll}
\hline & $\begin{array}{l}\text { First surgery } \\
(\mathrm{S} 1) n=713(\%)\end{array}$ & $\begin{array}{l}\text { Second surgery } \\
(\mathrm{S} 2) n=325(\%)\end{array}$ & $\begin{array}{l}3 \text { or more surgeries } \\
(\mathrm{S} 3) n=186(\%)\end{array}$ \\
\hline Shift of location Y/N & - & $51 / 274(16 \%, 84 \%)$ & $21 / 165(11 \%, 89 \%)$ \\
Anastomotic rec Y/N & - & $197 / 128(61 \%, 39 \%)$ & $103 / 83(55 \%, 45 \%)$ \\
Strictureplasty rec Y/N & - & $19 / 306(5 \%, 95 \%)$ & $23 / 163(12 \%, 88 \%)$ \\
Intraoperative procedures & & & \\
Small bowel resection & $582(44 \%)$ & $241(40 \%)$ & $127(38 \%)$ \\
Colonic resection & $177(14 \%)$ & $67(11 \%)$ & $25(8 \%)$ \\
SP & $318(24 \%)$ & $153(25 \%)$ & $102(30 \%)$ \\
NCSP & $243(19 \%)$ & $142(24 \%)$ & $76(23 \%)$ \\
$\quad 1311$ & 603 & 330 & \\
Total & & & $183 \pm 72$ \\
Duration of surgery & $158 \pm 68$ & $173 \pm 69$ & $172 \pm 62^{\mathrm{a}, \mathrm{c}}(n=126)$ \\
General & $158 \pm 68^{\mathrm{a}}$ & $163 \pm 60^{\mathrm{a}, \mathrm{b}}(n=228)$ & $198 \pm 74^{\mathrm{c}, \mathrm{d}}(n=60)$ \\
Previous domestic & - & $180 \pm 70^{\mathrm{b}, \mathrm{d}}(n=97)$ & $48 / 36 / 102$ \\
Previous foreign & $270 / 132 / 311$ & $115 / 96 / 114$ & $(26 \%, 19 \%, 55 \%)$ \\
Fistula/abscess /N & $(38 \%, 18 \%, 44 \%)$ & $(35 \%, 29 \%, 36 \%)$ & $30 / 156(16 \%, 84 \%)$ \\
& $72 / 641(10 \%, 90 \%)$ & $35 / 290(10 \%, 90 \%)$ & $12 / 174(6.4 \%)$
\end{tabular}

Surgical procedures are considered per segment, as more diseased segment could be comprised in one single resection or NCSP

Depending on whether their first operation was performed at domestic IBD Unit or in other hospitals the patientswere compared as follows: a: S1 vs S2 vs S3; b: S2 domestic vs S2 foreign; c: S3 domestic vs S3 foreign; c: S2 vsS3 foreign 
Table 3 Postoperative complications

\begin{tabular}{lcccc}
\hline & $\begin{array}{l}\text { First surgery } \\
(\mathrm{S} 1) n=713(\%)\end{array}$ & $\begin{array}{l}\text { Second surgery } \\
(\mathrm{S} 2) n=325(\%)\end{array}$ & $\begin{array}{l}3 \text { or more surgeries } \\
(\mathrm{S} 3) n=186(\%)\end{array}$ & $p$ \\
\hline Clavien-Dindo & & & & \\
I+ II & $118(17 \%)$ & $65(20 \%)$ & $40(21 \%)$ & \\
III & $60(8.4 \%)$ & $30(9.2 \%)$ & $19(10.2 \%)$ & \\
IV & $6(0.8 \%)$ & $5(1.5 \%)$ & $1(2.1 \%)$ & \\
V & $3(0.4 \%)$ & $2(0.6 \%)$ & $64(34.4 \%)$ & 0.04 \\
Total & $187(26.2 \%)$ & $102(31.4 \%)$ & $24(12.9 \%)$ & 0.2 \\
$\begin{array}{l}\text { Major complications } \\
\text { (III-V) }\end{array}$ & $69(9.6 \%)$ & $37(11.3 \%)$ & & \\
\hline
\end{tabular}

Fig. 1 Kaplan and Meier function showing the long-term surgical recurrence after each surgical procedure compared with the log-rank test

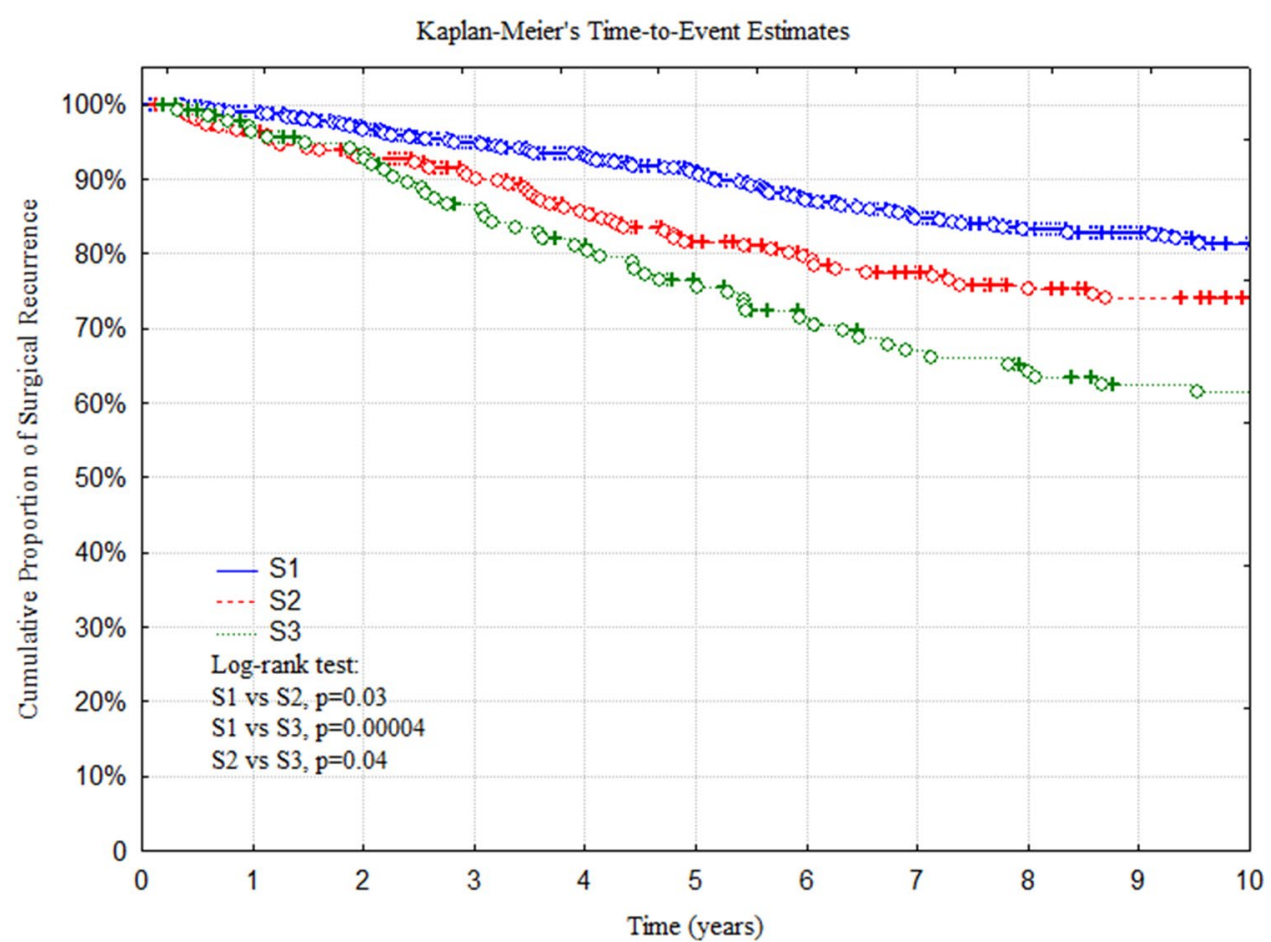

\section{Discussion}

This is the first study comparing the postoperative outcomes of patients with primary or recurrent $\mathrm{CD}$, comprising any intestinal location, and treated using a conservative strategy of minimal bowel resection and strictureplasties. Data regarding the outcome of surgery for single or multiple recurrent $C D$ are limited in the literature and focused on ileocolic disease [17-19, 22, 27]. Since CD is a chronic, relapsing disease, it is reasonable that the younger the age at diagnosis and the longer the disease duration, the higher the frequency of multiple recurrences, as showed in Table 1. However, as previously reported, young age at diagnosis (Montreal Classification A1), extensive bowel involvement (Montreal Classification L4), and short time-to-first surgery are definite factors involved in surgical disease recurrences [3, 9]. In fact, if perforating disease has to be considered a risk for recurrence in ileocecal and pure colonic locations, there is a welldefined sub-group of young patients, with extensive fibrostenotic disease, who are at high risk of repeated surgery and exhibit an indolent disease pattern difficult to control with current pharmacologic repertoire, as reported in the European Crohn's and Colitis Organisation-European Society of Coloproctology (ECCO-ESCP) 2018 guidelines $[9,15,16]$. This phenomenon is also evident in the longterm surgical recurrence rate which significantly increases after surgery for recurrent disease, suggesting that surgical recurrence is a definite risk for further recurrences, and adequate prophylactic therapies are still needed in this subgroup of patients [19]. 
More than half of the patients in S3 group (55\%) presented with nutritional impairment, despite the use of preoperative optimization with parenteral nutrition. These patients are also less likely to suspend immunosuppressive and biological therapy when scheduled for surgery, with a potential additional risk factor for post-operative complications [16]. All these features have to be taken into account in terms of clinical workload when planning a surgical procedure, in particular during the complicated period of the COVID-19 pandemic $[28,29]$.

Recurrences of CD are generally localized in the anastomotic territory of a previous resection ( $>60 \%)$, but after a SP or a NCSP the specific recurrence rate by site is reported to be very low $(<5 \%)[6,9,16,30,31]$. In the present study, while the first recurrence occurred on a strictureplasty site in line with the reported 5\% rate, the more the number of reinterventions, the more the recurrences on a strictureplasty site $(12 \%)$, data were never reported in the literature before. Nevertheless, the need for bowel length preservation after repeated surgery pushed the use of strictureplasty and re-do strictureplasty over the $50 \%$ of bowel segments in the S3 group. On the contrary, colonic resections decreased from $14 \%$ in S1 to 8\% in S3, suggesting that a bowel-sparing policy, together with adjuvant treatment, may positively impact on colonic disease recurrences [32, 33]. Furthermore, 16\% of the patients in $\mathrm{S} 2$ and $11 \%$ in $\mathrm{S} 3$ groups experienced a shift in the disease location, by having the recurrence in a different bowel district than primary surgery. This shift in CD location at time of surgical recurrence still represents a poorly understood and neglected phenomenon.

There was a significant increasing trend of performing strictureplasties, reoperation after reoperation $(42 \%-49 \%-$ $54 \%$ ) at the expense of bowel resections that conversely were less performed from S1 to S3 group (58\%-51\%-46\%). These results suggest that a conservative approach, specifically represented by SP or NCSP, should be the operation of choice in recurrent $\mathrm{CD}$ patients, whenever possible, due to the low recurrence rate on a SP site and the associated lower rate of SBS.

Defining the degree of difficulty of a surgical intervention is a challenging issue in daily practice, since the countless different clinical, anatomical, and technical factors are involved. However, the duration of surgery turns out to be quite a reliable parameter (even though non-specific), especially because all the surgical procedures in this series have been performed by a small group of surgeons, with a standardized technique maintained over the years. Duration of surgery had an increasing trend at repeated surgeries, but it was not statistically significant for those patients operated at "Luigi Sacco" IBD Unit since the first operation. On the other side, those patients referred to the IBD Unit after the first surgery was performed in other hospitals required longer operating time for both first and further recurrences.
Also, the incidence of short bowel syndrome (SBS) is related to the number of surgical procedures received from the patients. In the literature, SBS cumulative risk is reported to be of $0.8 \%$ at 5 years, $3.6 \%$ at 10 years, and $8.5 \%$ at 20 years [34-36]. In this series, probably due to the highly conservative approach of minimal bowel re-resections and strictureplasties, the SBS incidence in S1 group was $0.1 \%$, with a disease duration of $6.8 \pm 7$ years; in S2 group $1.5 \%$, with a disease duration of $12 \pm 6.9$ years; and in S3 group was $6.4 \%$, with a disease duration of $17.3 \pm 8.6$ years $(p<0.0001)$. However, only 2 out of 12 patients $(16 \%)$ were operated at the "Luigi Sacco" IBD Unit for the first and second surgical procedure, while the remaining 10 patients $(83 \%)$ were referred after previous extensive small bowel resections performed in other hospitals. The lower frequency of SBS and the shorter operating time in those patients treated and followed up from the very beginning at "Luigi Sacco" IBD Unit suggest the importance of referring IBD patients to dedicated surgeons [23].

All the authors that examined the outcome of $\mathrm{CD}$ patients undergone to multiple surgeries agreed that recurrences are technically demanding due to postoperative adhesions, modified anatomy, and complex perforating disease, but without a significant increase in severe post-operative complications. In this series, the overall postoperative complication rate was $28 \%$ and major complication rate $10 \%$, with a difference in minor $(p=0.04)$ but not major $(p=0.2)$ Clavien-Dindo complication rate among all groups. A result similar to that reported in the series focused on terminal ileum disease [17-19, 21, 22, 27]. Heimann et al. reported that a disease requiring multiple re-operations is more aggressive and is more likely to result in complex resections and permanent ileostomy, in line with the results of the present series [20].

Some limitations have to be considered in the interpretation of the study results: this is a retrospective analysis of a prospective database, from a single tertiary center, covering a long-term period of 25 years. If the surgical strategy has been maintained almost unchanged over the years, the surgical approach has been shifted from open to laparoscopic surgery, and the adjuvant medical therapy has been enriched with the addition of novel biological therapies [3-6, 9, 37-39]. However, laparoscopy was adopted for CD by the "Luigi Sacco" IBD Unit since 2007, but it was offered only to the patients at their first operation or those presenting with a recurrence after a previous laparoscopic surgery. Those patients treated by previous open surgery were not candidate to laparoscopy. This approach would minimize and equalize the effect of laparoscopy among the different groups [38-40]. The effect of adjuvant therapy on postoperative recurrence is not in the aims of the present study. On the one hand, surgical recurrence is a long-term event and during the years, several therapeutic changes could be made in every single patient, making it almost impossible to evaluate 
the potential effect of each drug in a very long period. On the other hand, the use of therapies over the years, following the updated guidelines, has probably had a uniform distribution in the series.

\section{Conclusion}

Repeated surgery for complicated CD is associated with an increase in minor, but not major Clavien-Dindo complications rate. It requires a longer operating time, with a potential for augmented ostomies and SBS. Patients operated from the first operation in a referral center, with a dedicated IBD team, are less likely to undergo complex procedures with extensive resections in the following surgery for recurrence. Long-term surgical recurrence rate after repeated surgery remains high and a bowel-sparing strategy appears to be more favorable in terms of further recurrences and SBS risk.

\begin{abstract}
Acknowledgements This series included many patients who were under the care of Professor Gabriele Bianchi Porro and Professor Roberto de Franchis, the former Chiefs and Chairs of the Division of Gastroenterology, and thus their contributions are gratefully acknowledged. A special thought and a thank you to Professor Angelo Maria Taschieri, former head of the Department of Surgery. Many thanks to the non-profit, volunteer-fuelled, patient organization M.I.Cro. Italia ODV, for their support to us and our patients.
\end{abstract}

Funding None of the authors received any fund for this study.

\section{Declarations}

Conflict of interest None of the authors have conflicts to declare.

\section{References}

1. Crohn BB, Ginzburg L, Oppenheimer GD (1932) Regional ileitis: a pathological and clinical entity. JAMA 99:1323-1329

2. Bernell O, Lapidus A, Hellers G (2000) Risk factors for surgery and postoperative recurrence in Crohn's disease. Ann Surg 231:38-45

3. Cristaldi M, Sampietro GM, Danelli PG, Bollani S, Bianchi Porro G, Taschieri AM (2000) Long-term results and multivariate analysis of prognostic factors in 138 consecutive patients operated on for Crohn's disease using "bowel-sparing” techniques. Am J Surg 179:266-270

4. Maconi G, Sampietro GM, Cristaldi M et al (2001) Preoperative characteristics and postoperative behavior of bowel wall on risk of recurrence after conservative surgery in Crohn's disease: a prospective study. Ann Surg 233:345-352

5. Parente F, Sampietro GM, Molteni M et al (2004) Behaviour of the bowel wall during the first year after surgery is a strong predictor of symptomatic recurrence of Crohn's disease: a prospective study. Aliment Pharmacol Ther 20:959-968

6. Sampietro GM, Cristaldi M, Maconi G, et al. A prospective, longitudinal study of nonconventional strictureplasty in Crohn's disease. Journal of the American College of Surgeons 2004;199:820 ; discussion -2 .
7. Michelassi F, Taschieri A, Tonelli F et al (2007) An international, multicenter, prospective, observational study of the side-to-side isoperistaltic strictureplasty in Crohn's disease. Dis Colon Rectum 50:277-284

8. Maconi G, Colombo E, Sampietro GM et al (2009) CARD15 gene variants and risk of reoperation in Crohn's disease patients. Am J Gastroenterol 104:2483-2491

9. Sampietro GM, Corsi F, Maconi G et al (2009) Prospective study of long-term results and prognostic factors after conservative surgery for small bowel Crohn's disease. Clin Gastroenterol Hepatol Off Clin Pract J Am Gastroenterol Assoc 7:183-191

10. Simillis C, Yamamoto T, Reese GE et al (2008) A meta-analysis comparing incidence of recurrence and indication for reoperation after surgery for perforating versus nonperforating Crohn's disease. Am J Gastroenterol 103:196-205

11. Satsangi J, Silverberg MS, Vermeire S, Colombel JF (2006) The Montreal classification of inflammatory bowel disease: controversies, consensus, and implications. Gut 55:749-753

12. Gasche C, Scholmerich J, Brynskov J et al (2000) A simple classification of Crohn's disease: report of the working party for the world congresses of gastroenterology, Vienna 1998. Inflamm Bowel Dis 6:8-15

13. Rutgeerts P, Geboes K, Vantrappen G, Beyls J, Kerremans R, Hiele M (1990) Predictability of the postoperative course of Crohn's disease. Gastroenterology 99:956-963

14. Coffey CJ, Kiernan MG, Sahebally SM et al (2018) Inclusion of the mesentery in ileocolic resection for Crohn's disease is associated with reduced surgical recurrence. J Crohns Colitis 12:1139-1150

15. Gionchetti P, Dignass A, Danese S et al (2017) 3rd European evidence-based consensus on the diagnosis and management of Crohn's disease 2016: part 2: surgical management and special situations. J Crohns Colitis 11:135-149

16. Bemelman WA, Warusavitarne J, Sampietro GM et al (2018) ECCO-ESCP consensus on surgery for Crohn's disease. J Crohns Colitis 12:1-16

17. Brouquet A, Blanc B, Bretagnol F, Valleur P, Bouhnik Y, Panis Y (2010) Surgery for intestinal Crohn's disease recurrence. Surgery 148:936-946

18. Brouquet A, Bretagnol F, Soprani A, Valleur P, Bouhnik Y, Panis Y (2010) A laparoscopic approach to iterative ileocolonic resection for the recurrence of Crohn's disease. Surg Endosc 24:879-887

19. Iborra M, Juliá B, Martín Arranz MD et al (2019) Management and outcomes of patients with Crohn's disease with first vs multiple surgeries: results from the PRACTICROHN study. Gastroenterol Rep (Oxf) 7:411-418

20. Heimann TM, Greenstein AJ, Lewis B, Kaufman D, Heimann DM, Aufses AH Jr (1998) Comparison of primary and reoperative surgery in patients with Crohns disease. Ann Surg 227:492-495

21. Abdalla S, Brouquet A, Maggiori L et al (2019) Postoperative morbidity after iterative ileocolonic resection for Crohn's disease: should we be worried? A prospective multicentric cohort study of the GETAID chirurgie. J Crohns Colitis 13:1510-1517

22. Bouquot M, Maggiori L, Hain E, Prost ADJ, Bouhnik Y, Panis $\mathrm{Y}$ (2019) What is the outcome for patients undergoing more than two ileocolonic resections for recurrent Crohn's disease? A comparative study of 569 consecutive procedures. Colorectal Dis Off J Assoc Coloproctol Great Br Irel 21:563-569

23. Sampietro GM, Colombo F, Frontali A et al (2021) Strictureplasties performed by laparoscopic approach for complicated Crohn's disease. A prospective, observational, cohort study. Digest Liver Dis. https://doi.org/10.1016/j.dld.2021.01.023

24. Dindo D, Demartines N, Clavien P-A (2004) Classification of surgical complications. Ann Surg 240:205-213 
25. von Elm E, Altman DG, Egger M et al (2007) The strengthening the reporting of observational studies in epidemiology (STROBE) statement: guidelines for reporting observational studies. Lancet 370:1453-1457

26. Association WM (2013) World medical association declaration of Helsinki: ethical principles for medical research involving human subjects. JAMA 310:2191-2194

27. Pinto RA, Shawki S, Narita K, Weiss EG, Wexner SD (2011) Laparoscopy for recurrent Crohn's disease: how do the results compare with the results for primary Crohn's disease? Colorectal Dis 13:302-307

28. Occhipinti V, Saibeni S, Sampietro GM, Pastorelli L (2020) Impact of COVID-19 outbreak on the management of patients with severe IBD: a domino effect. Gastroenterology 160:2196

29. Sampietro GM, Corbellini C, Baldi C et al (2020) Surgery safety protocol for patients and staff during the covid-19 global pandemic - a prospective study of 78 consecutive, open and laparoscopic surgical procedures. Surg Case Rep. https://doi.org/10. 31487/j.SCR.2020.12.28

30. Yamamoto T, Fazio VW, Tekkis PP (2007) Safety and efficacy of strictureplasty for Crohn's disease: a systematic review and metaanalysis. Dis Colon Rectum 50:1968-1986

31. Campbell L, Ambe R, Weaver J, Marcus SM, Cagir B (2012) Comparison of conventional and nonconventional strictureplasties in Crohn's disease: a systematic review and meta-analysis. Dis Colon Rectum 55:714-726

32. Scaringi S, Di Bella A, Boni L et al (2018) New perspectives on the long-term outcome of segmental colectomy for Crohn's colitis: an observational study on 200 patients. Int J Colorectal Dis 33:479-485

33. Angriman I, Pirozzolo G, Bardini R, Cavallin F, Castoro C, Scarpa M (2017) A systematic review of segmental vs subtotal colectomy and subtotal colectomy vs total proctocolectomy for colonic Crohn's disease. Colorectal Dis 19:e279-e287

34. Thompson JS (1987) Strategies for preserving intestinal length in the short bowel syndrome. Dis Colon Rectum 30:208-213

35. Yamamoto T, Allan RN, Keighley MR (2001) Long-term outcome of surgical management for diffuse jejunoileal Crohn's disease. Surgery 129:96-102

36. Fuglestad MA, Thompson JS (2019) Inflammatory bowel disease and short bowel syndrome. Surg Clin North Am 99:1209-1221

37. Sampietro GM, Colombo F, Frontali A et al (2018) Totally laparoscopic, multi-stage, restorative proctocolectomy for inflammatory bowel diseases. A prospective study on safety, efficacy and long-term results. Digest Liver Dis 50:1283-1291

38. Alessandroni L, Bertolini R, Campanelli A et al (2010) Videoassisted versus open ileocolic resection in primary Crohn's disease: a comparative case-matched study. Updat Surg 62:35-40

39. Tiberi A, Pesi B, Giudici F et al (2020) Laparoscopic ileo-colic resection and right hemicolectomy for Crohn's disease and colon cancer: a preliminary comparative study on post-operative outcome. Updat Surg 72:821-826

40. D'Ugo S, Romani F, Sibio S et al (2020) Impact of surgery on quality of life in Crohn's disease: short- and mid-term follow-up. Updat Surg 72:773-780

Publisher's Note Springer Nature remains neutral with regard to jurisdictional claims in published maps and institutional affiliations. 